\title{
Design and Performance Evaluation of a Very Low Flow Coefficient Centrifugal Compressor
}

\author{
Yongsheng Wang, ${ }^{1,2}$ Feng Lin, ${ }^{1}$ Chaoqun Nie, ${ }^{1}$ and Abraham Engeda ${ }^{3}$ \\ ${ }^{1}$ Key Laboratory of Advanced Energy and Power Chinese Academy of Sciences, Institute of Engineering Thermophysics, \\ Chinese Academy of Sciences, Beijing 100190, China \\ ${ }^{2}$ Graduate University of Chinese Academy of Sciences, Beijing 100190, China \\ ${ }^{3}$ Department of Mechanical Engineering, Michigan State University, East Lansing, MA 48823, USA
}

Correspondence should be addressed to Yongsheng Wang; wangyongsheng@iet.cn

Received 1 August 2013; Accepted 16 September 2013

Academic Editor: Masaru Ishizuka

Copyright (C) 2013 Yongsheng Wang et al. This is an open access article distributed under the Creative Commons Attribution License, which permits unrestricted use, distribution, and reproduction in any medium, provided the original work is properly cited.

\begin{abstract}
Very low flow coefficient centrifugal compressors are often applied as the last stages of multistage compressors. Due to the lower volume flow rate, the flow channels in the impeller and diffuser are so narrow that friction loss becomes the main factor, which leads to lower efficiency than that of other stages in the same compressors. In addition, most of design methods are generally based on medium flow coefficient centrifugal compressors. Taking on researches on the low flow coefficient centrifugal compressors is significant and necessary. One-dimensional (1D) code, consisting of design and analysis parts, is developed in this study to provide basic geometric data and predict the entire performance of centrifugal compressor. Three-dimensional geometry of the impeller is built. CFD simulation is carried out as well to be compared with $1 \mathrm{D}$ prediction. With the continuous geometry adjustment, the final performance of the centrifugal compressor will be fixed once the performance discrepancy between CFD and one-dimensional code is acceptable. The details on the flow field within impeller will be presented through CFD.
\end{abstract}

\section{Introduction}

Centrifugal compressors are usually designed in the flow coefficient range $\varphi=0.01$ to 0.16 . Often the need arises to design very low or high flow coefficient, $\varphi$, radial stages, but the aerodynamic challenges are not easy to satisfy; therefore, a designer usually has to make certain critical decisions. Figure 1 shows the typical application area of various compressor impellers and the typical areas where most industrial radial impellers are designed. Narrow radial impellers (smaller $\varphi$ and smaller eye diameter) have nontwisted blades. Wider impellers (larger $\varphi$ and larger eye diameter) by contrast have twisted blades for better adaption to local flow conditions.

In very low flow coefficients stage design, the major challenges are mechanical configuration and diffuser stability, and most significantly the aerodynamic and parasitic losses are substantial as seen in Figure 1.
Low flow coefficient compressors are used for many applications in industry and generally found as the last stages of multistage compressors where the volume rate is lower. Twodimensional radial impeller is usually applied. Compared to the centrifugal compressors with considerably higher flow coefficient, the range of very low flow coefficient centrifugal compressors is between 0.007 and 0.02 . It means that a low volume flow rate passes through the impeller relative to the outlet diameter and peripheral speed. This causes special problems in obtaining an acceptable efficiency, which is mainly affected by three sources of efficiency losses: skin friction, disc friction, and leakage. These compressors have generally a very narrow impeller channel that leads to high friction losses. The power required to overcome disc friction and leakage is in the same order as a conventional higher flow stage. Therefore, efficient design of low flow coefficient centrifugal compressors still needs more great effort from the designers. Moreover, in the most recent years, the demand for 


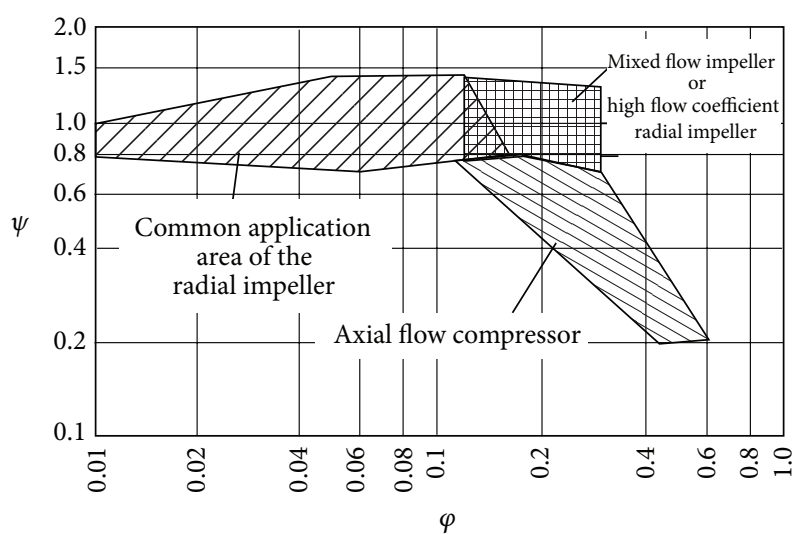

(a)

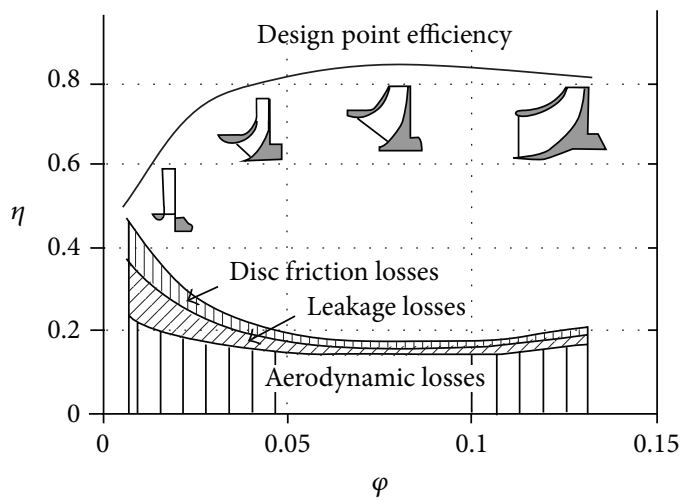

(b)

FIGURE 1: Application areas of high flow coefficient radial impellers and typical industrial compressors [1].

such high pressure ratio compressor operating at low flow rate has risen. Nevertheless, little information is available concerning low flow coefficient centrifugal compressor design in the open literature. The following descriptions review some research work regarding design of low flow coefficient centrifugal compressors.

Rusak [3] briefly presented three types of impeller design for low flow application: low flow conventional stages with 2D impellers, low flow high pressure coefficient stages with radial impellers, and very low flow stages with wedge-type impellers. Casey et al. [4] designed and tested several low flow coefficient centrifugal compressors with high head and low outlet meridional velocity component. Koizumi [5] designed three different compressors with straight blades, S-shaped blades, and almost radial blades. In the mean time, the influence of the viscous effect on the slip factor was studied and the stall-onset condition for rotating stall in the vaneless diffuser following the impeller was investigated as well. Paroubek et al. [6] tested six conventional low flow coefficient impellers. The effects of inducer hub to exit shroud diameter ratio and channel width parameter on the stage performances were investigated. Di Liberti [7] designed several lowflow-coefficient impellers and analyzed them numerically to investigate the effect of the design flow coefficient, of the outlet width-outlet blade angle combination, and of the blade leading edge position on the stage performance. Biba et al. [8] used commercial CFD codes together with in-house program design and analyzed two different impellers with low volume flows and high pressure applications.

Based on the above research results, this study aims to design an efficient low flow coefficient centrifugal compressor with wide operating range. MATLAB is used as a tool to develop $1 \mathrm{D}$ design and analysis codes. The three-dimensional geometry model of impeller is built by "BLADEGEN". Once CFD indicates that the performance of centrifugal compressor is satisfactory and has an acceptable discrepancy with 1D prediction, the final geometry of impeller will be fixed and design process is terminated.

\section{1D Design and Analysis Methods}

1D code developed in this paper is divided into two parts: design and analysis parts. Design part provides basic geometric data of impeller at design point. Based on the geometry, analysis part can do the performance analysis using empirical loss models at design and off-design points [9] and export the whole performance curve of the centrifugal compressor. It is necessary to keep adjusting geometry until the comparison of CFD and $1 \mathrm{D}$ codes shows that discrepancy is acceptable and design goals have been reached. The $1 \mathrm{D}$ design and analysis scheme is illustrated in Figure 2. Clearance loss and recirculation loss are excluded in this shrouded impeller. In fact, hub-to-shroud loss and choke loss are not activated as well, which will be discussed in the following section of this paper.

In the case of this paper, mass flow rate $(m)$, inlet total pressure of impeller $\left(P_{01}\right)$, inlet total temperature of impeller $\left(T_{01}\right)$, rotational speed of impeller $(N)$, impeller outlet diameter $\left(D_{2}\right)$, and hub diameter $\left(D_{h}\right)$ are given. The working medium is natural gas and typical composition is used while setting the fluid properties in CFD. In the design part, the values of $V_{m 2} / U_{2}, \beta_{2 b}$ [10] and $V_{u 2} / V_{u 2 b}$ are assumed within empirical ranges. With these parameters, impeller outlet calculation can be completed. Then, in order to calculate impeller inlet aerodynamic parameters, the ratios of $D_{1} / D_{2}$ and $W_{2} / W_{1}$ must be chosen to relate outlet to inlet. Since the inlet flow coefficient is 0.022 , impeller inlet should be located in the radial direction, which means that inlet hub diameter is equal to inlet shroud diameter [2]. It is because the return channel upstream of low coefficient compressor in the real application guides the flow to be more uniform. Inducer can be neglected, which reduces flow path in the impeller and produces less skin friction loss. Meanwhile, impeller axial length $\left(L_{z}\right)$ can be determined as well. Number of the blades $(Z)$ comes from original slip factor formula of Wiesner [11].

Analysis part only includes one input variable, which is mass flow rate. In the following analysis procedure, fluid density at impeller inlet is initially approximated and requires 


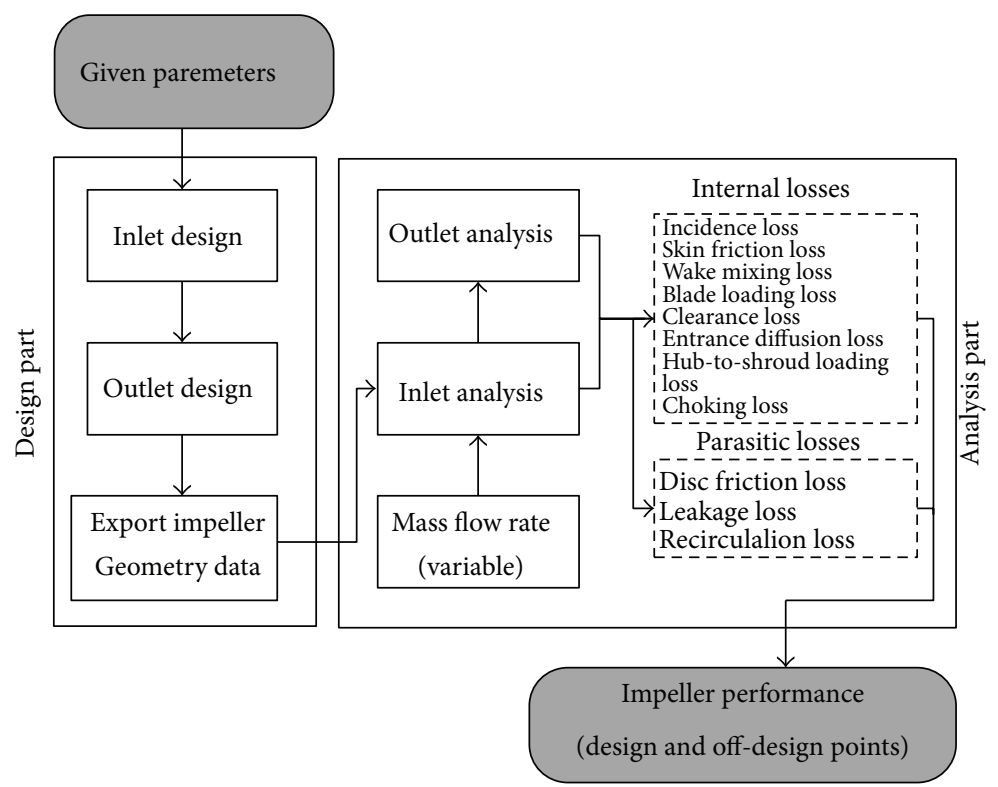

FIgURE 2: Flow chart of 1D code.

an iterative solution procedure with the constraint of iteration error being less than $0.1 \%$. The same iterative method is applied until convergence is reached on the fluid density calculation at impeller outlet, in which internal losses are involved and used for computing impeller efficiency, total pressure, static pressure, and density. The equations used in the analysis part will be introduced, and the related state functions and loss models are included.

Specific heat at constant pressure is given as a constant provided by industry in this design case. No preswirl exists at the impeller inlet, which makes $V_{u 1}=0$ and $V_{1}=V_{m 1}$. Inlet gas density is initialized by the following equation:

$$
\rho_{1} \approx \rho_{01}=\frac{P_{01}}{\left(R T_{01}\right)} \text {. }
$$

According to the fixed geometry data and given design parameters, the values of $V_{m 1}, U_{1}, W_{1}$, and $W_{\text {th }}$ can be easily calculated. Equation (2) below provide the rest of thermodynamic parameters:

$$
\begin{gathered}
T_{1}=T_{01}-\frac{V_{1}^{2}}{\left(2 C_{p}\right)}, \\
P_{1}=P_{01}\left(\frac{T_{1}}{T_{01}}\right)^{k /(k-1)}, \\
\rho_{1^{\prime}}=\frac{P_{1}}{\left(R T_{1}\right)} .
\end{gathered}
$$

The inlet calculation will be done once the iteration shows that the difference between two density values is within the error range shown in Figure 3. Before moving on to the impeller outlet calculation, fraction area blockage at impeller exit $\left(B_{2}\right)$ has to be initially approximated first and updated later. Then, $V_{u 2}$ can be given after slip factor calculation is completed:

$$
\begin{gathered}
\rho_{2}=\rho_{1}\left(\frac{U_{2}^{2}}{\left(C_{p} T_{01}\right)}+1\right)^{1 /(k-1)}, \\
V_{m 2}=\frac{m}{\left(\pi \rho_{2} D_{2} b_{2}\left(1-B_{2}\right)\right)}, \\
\sigma=1-\frac{\sqrt{\sin \left(\beta_{2 b}\right)} \sin \left(\alpha_{2 c}\right)}{Z^{0.7}}, \\
e_{\lim }=\frac{\left(\sigma-\sin \left(19+2 \beta_{2 b}\right)\right)}{\left(1-\sin \left(19+2 \beta_{2 b}\right)\right)}, \\
e=\frac{D_{1}}{D_{2}} .
\end{gathered}
$$

$$
\begin{gathered}
\text { If } e>e_{\lim }, \quad \sigma=\sigma\left(1-\left(\frac{\left(e-e_{\lim }\right)}{\left(1-e_{\lim }\right)}\right)^{\sqrt{\beta_{2 b} / 10}}\right), \\
V_{u 2}=\sigma\left(U_{2}-\frac{V_{m 2}}{\tan \left(\beta_{2 b}\right)}\right), \\
T_{01}^{\wedge}=T_{1}+\frac{W_{1}^{2}}{\left(2 C_{p}\right)} \\
T_{02}^{\wedge}=T_{01}^{\wedge}+\frac{\left(U_{2}^{2}-U_{1}^{2}\right)}{\left(2 C_{p}\right)} .
\end{gathered}
$$




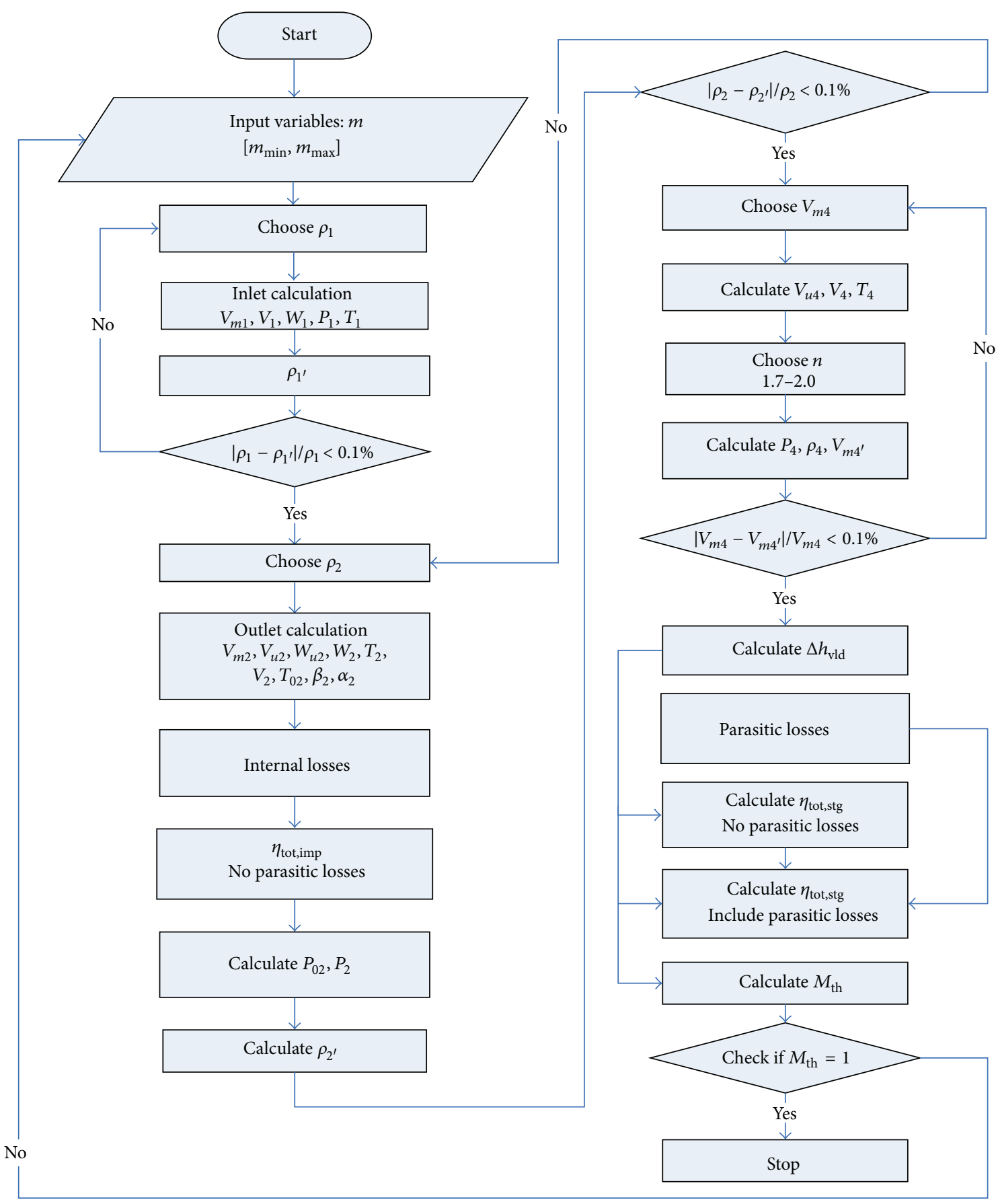

FIGURE 3: Detailed flow chart of 1D analysis part.

So, $W_{u 2}, W_{2}, V_{2}$, and flow angles can be easily obtained based on basic impeller outlet velocity triangle. Then, (4) will provide $T_{2}$ and $T_{02}$ :

$$
\begin{aligned}
& T_{2}=T_{02}^{\wedge}-\frac{W_{2}^{2}}{\left(2 C_{p}\right)}, \\
& T_{02}=T_{01}+\frac{U_{2} V_{u 2}}{C_{p}} .
\end{aligned}
$$

Then, all the internal losses and parasitic losses calculation can be finished. Detailed equations regarding loss models can be found in [2]. $B_{2}$ can be updated by (5):

$$
\begin{gathered}
B_{2^{\prime}}=\frac{\left(h_{\mathrm{sf}}+h_{\mathrm{hs}}\right)}{W_{2}^{2}}+\left(0.3+\frac{b_{2}^{2}}{L_{B}^{2}}\right) \frac{A R^{2} b_{2} \rho_{2}}{\left(\rho_{1} L_{B}\right)} \\
\eta_{\mathrm{I}}=\frac{C_{p}\left(T_{02}-T_{01}\right)-\left(\Delta h_{\mathrm{inc}}+\Delta h_{\mathrm{bl}}+\Delta h_{\mathrm{sf}}+\Delta h_{\mathrm{mix}}+\Delta h_{\mathrm{dif}}\right)}{C_{p}\left(T_{02}-T_{01}\right)} .
\end{gathered}
$$


If parasitic losses are included, a revised formula (7) should be applied:

$$
\eta_{\mathrm{II}}=\frac{C_{p}\left(T_{02}-T_{01}\right)-\left(\Delta h_{\mathrm{inc}}+\Delta h_{\mathrm{bl}}+\Delta h_{\mathrm{sf}}+\Delta h_{\mathrm{mix}}+\Delta h_{\mathrm{dif}}\right)}{C_{p}\left(T_{02}-T_{01}\right)+\Delta h_{\mathrm{df}}+\Delta h_{l}} .
$$

Finally, density at impeller outlet is updated and compared with the initial one:

$$
\begin{gathered}
T_{02 \text { is }}=T_{01}+\eta_{\mathrm{I}}\left(T_{02}-T_{01}\right), \\
P_{02}=P_{01}\left(\frac{T_{02 \mathrm{is}}}{T_{01}}\right)^{k /(k-1)}, \\
P_{2}=P_{02}\left(\frac{T_{02}}{T_{2}}\right)^{k /(k-1)}, \\
\rho_{2^{\prime}}=\frac{P_{2}}{\left(R T_{2}\right)} .
\end{gathered}
$$

The code will continue running until density at impeller outlet converges. If vaneless diffuser is involved in the analysis part, the corresponding loss model shown in Figure 3 has to be added.

Internal losses mainly include incidence loss, blade loading loss, skin friction loss, wake mixing loss, hub-to-shroud loading loss, entrance diffusion loss, and clearance loss [2, 12]. Generally, parasitic losses are not involved in CFD. In order to make an efficiency comparison with or without parasitic losses, disc friction, recirculation, and leakage are also taken into consideration. In this case, clearance loss and leakage loss are not considered due to shrouded impeller.

Besides the above descriptions, how to predict stall and choke point in the analysis part must be mentioned here, because these two points determine the operating range of centrifugal compressor directly. In Figure 3, mass flow rate as the only input variable has a range coming from design part directly. The initial value of mass flow rate at choke point is predicted in design part by (9) developed by Dixon [13]. Actually, (9) always overpredicts mass flow rate, which is because aerodynamic blockage at impeller throat is not considered. Therefore, it is appropriate to apply (9) to obtain larger mass flow rate for choke point first. The initialization of mass flow rate for stall point calculated in design part is to use critical absolute flow angle at diffuser inlet, which is computed by (10). Pinch between impeller outlet and diffuser inlet is also considered if applied [14]:

$$
\begin{gathered}
m_{\text {choke }}=A_{\text {th }} \rho_{01} a_{01}\left[\frac{2+(k-1) U_{1}^{2} / a_{01}^{2}}{k+1}\right]^{(k+1) / 2(k-1)}, \\
\alpha_{3 c}^{*}=\alpha_{3 c}+\left(17.02-\frac{148.4 b_{2}}{d_{2}}\right)\left(1-\frac{b_{3}}{b_{2}}\right) .
\end{gathered}
$$

In the analysis part, for stall point prediction, two methods are adopted. The main one used by majority designers is to check if $W_{1 s} / W_{\text {th }} \geq 1.75$, which seemed as an inducer stall criterion. The second option is to estimate equivalent

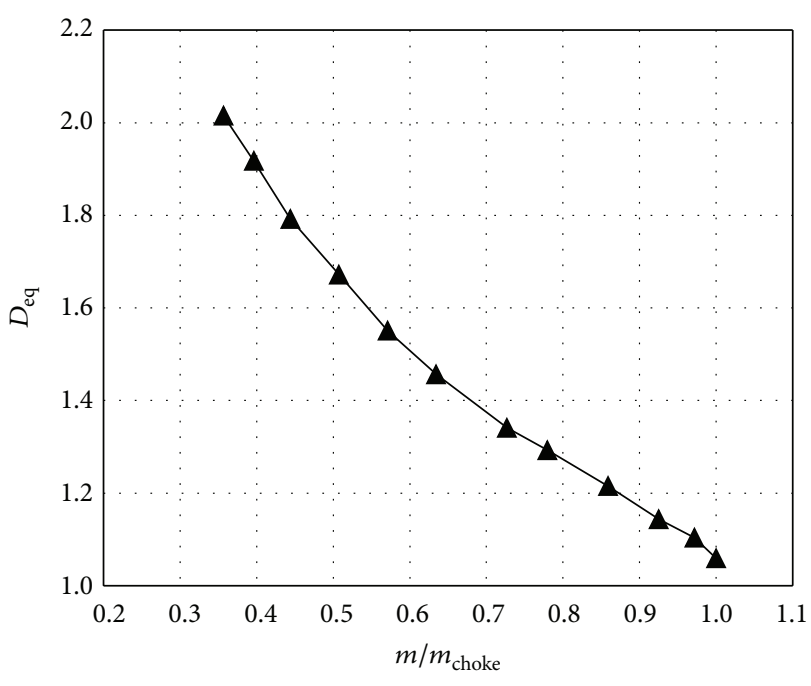

Figure 4: Equivalent diffusion factor.

diffusion factor $\left(D_{\text {eq }}\right)$. Lieblein [15] found that blade stall occurs in the axial compressor when $D_{\text {eq }}$ is bigger than 2 . Later on, $D_{\text {eq }}$ is generalized to radial and mixed flow blades to evaluate the blade loading. This criterion is also found to be an appropriate blade stall limit for impellers [2]. The related calculation equations are shown below. $D_{\text {eq }}$ is checked at every iteration step in analysis part to see if it reaches the criteria or not. If neither $W_{1 s} / W_{\mathrm{th}}$ nor $D_{\mathrm{eq}}$ indicates the compressor stalls, the initial mass flow rate value from (10) will be considered to be the minimum value:

$$
\begin{gathered}
D_{\text {eq }}=\frac{W_{\max }}{W_{2}}, \\
W_{\max }=\frac{\left(W_{1}+W_{2}+\Delta W\right)}{2}, \\
\Delta W=\frac{2 \pi D_{2} U_{2} I_{B}}{\left(Z L_{B}\right)} .
\end{gathered}
$$

Finally, in this case $1 \mathrm{D}$ code points out to $D_{\text {eq }}$, which is detected beyond the critical value first. The distribution of $D_{\text {eq }}$ over mass flow rate is shown in Figure 4. Based on the case in this paper, it is still hard to determine which method is suitable to stall point prediction so far. According to CFD simulation and test data, further evaluation of the 1D code needs to be done through huge number of impellers, which will be focused on in the future research work.

As for choke point calculation, iterative method is applied until relative Mach number at the impeller throat reaches 1. Generally, choke mass flow rate from analysis part is smaller than initialization based on (9). In this case, $1 \mathrm{D}$ code predicts choke mass flow rate at $80 \mathrm{~kg} / \mathrm{s}$ and CFD shows it at $81.55 \mathrm{~kg} / \mathrm{s}$. The difference is less than $2 \%$. However, the initial value is $89.54 \mathrm{~kg} / \mathrm{s}$ larger than analysis code prediction as expected.

Since mass flow rate in analysis part is increased by specific growth increment, the real operating range of the centrifugal compressor will be fixed after choke point calculation is done. The code will plot the entire performance 


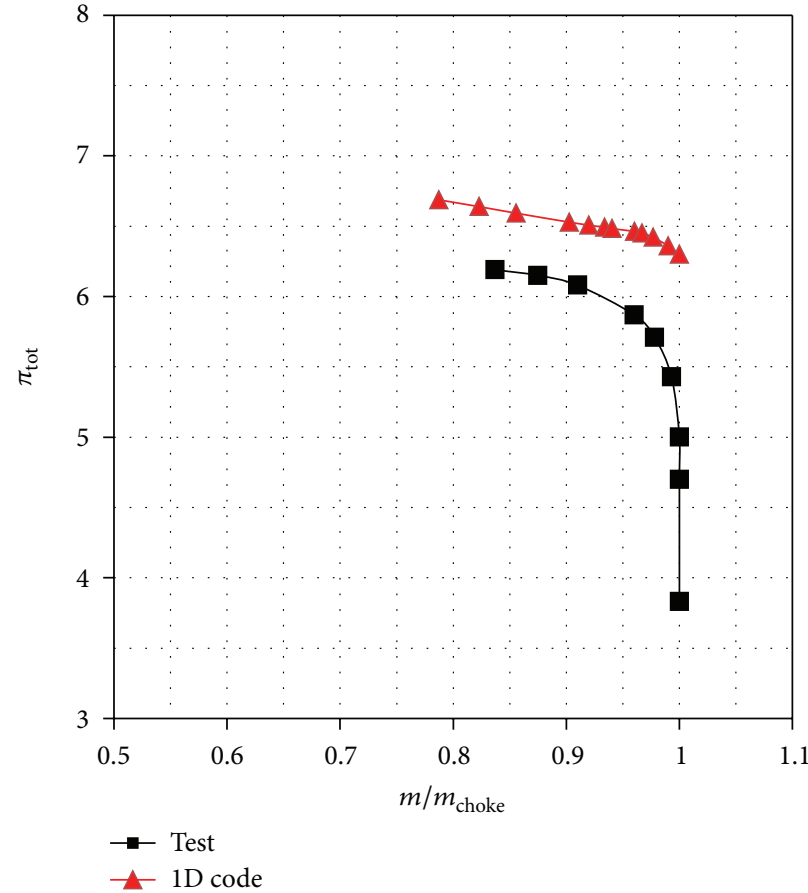

(a) Adiabatic efficiency

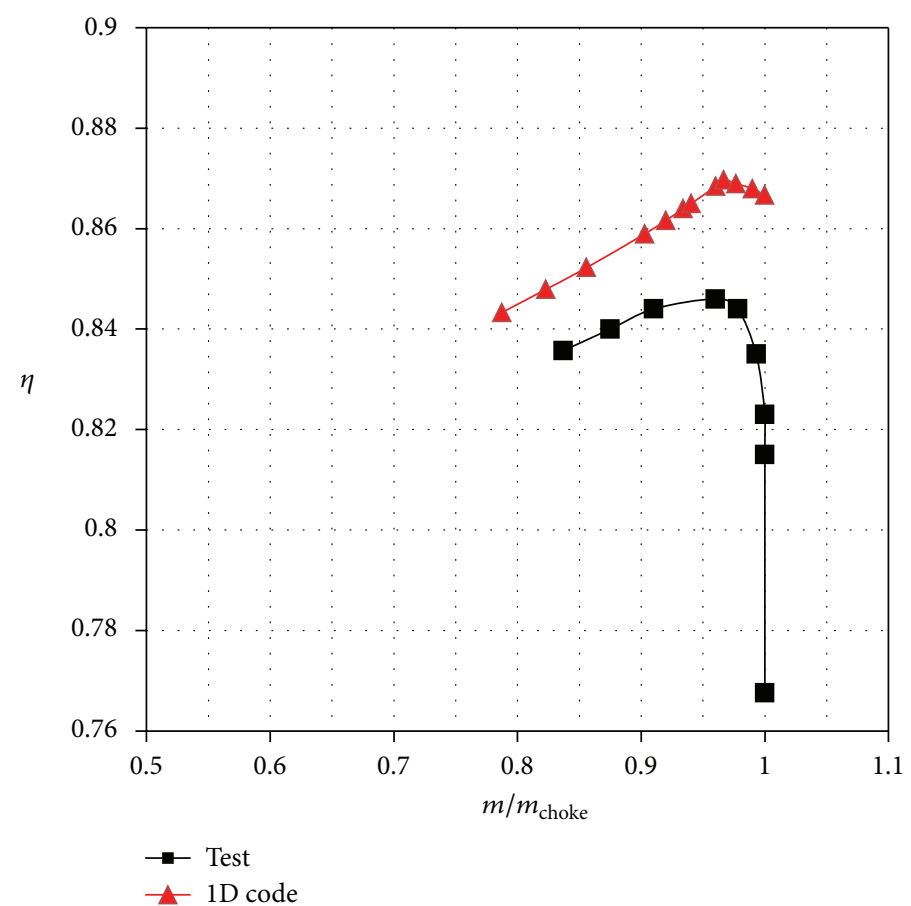

(b) Total pressure ratio

Figure 5: Performance curves between 1-D and test.

of the centrifugal compressor automatically including design and off-design points.

$1 \mathrm{D}$ analysis code was calibrated by the test data of one of three Krain's impellers [16, 17]. In Figure 5, it is obvious that total pressure ratio and adiabatic efficiency show similar distribution trend and the discrepancies between performance curves are acceptable. Compared to the test, wider surge margin is obtained by $1 \mathrm{D}$ code. Overall, based on this case, 1D analysis code is functional and satisfying. Also, a detailed flow parameter comparison of $1 \mathrm{D}$ code and test data of a high flow coefficient centrifugal compressor have been carried out, which also indicates good predictive effect of $1 \mathrm{D}$ analysis code. The related results are not shown here.

\section{1D Design and Analysis Results}

Main impeller geometric parameters from 1D code are listed in Table 1. Design parameters like mass flow rate, rotational speed, impeller outlet diameter, and shaft diameter are provided by industry according to practical demand.

Since leading edge and trailing edge of the impeller have the same streamline slope angle in this case, hub-to-shroud loss model is not activated. The criterion in the choking loss model is not satisfied and the choking loss is also not considered as well. Recirculation loss is neglected due to the shrouded impeller designed in this study.

Therefore, internal losses actually used include wake mixing loss, skin friction loss, incidence loss, blade loading loss, and inducer diffusion loss. Figure 6 shows loss coefficient distribution of impeller. It is observed that skin
TABLE 1: Impeller parameters.

\begin{tabular}{lc}
\hline$m$ & $48 \mathrm{~kg} / \mathrm{s}$ \\
$N$ & $12800 \mathrm{rpm}$ \\
$\varphi$ & 0.022 \\
$N_{s}$ & 0.07 \\
$D_{1}$ & $0.2172 \mathrm{~m}$ \\
$D_{2}$ & $0.381 \mathrm{~m}$ \\
$b_{1}$ & $0.0123 \mathrm{~m}$ \\
$b_{2}$ & $0.0082 \mathrm{~m}$ \\
$\beta_{1 b}$ & $28.9^{\circ}$ \\
$\beta_{2 b}$ & $40^{\circ}$ \\
$L_{z}$ & $0.0193 \mathrm{~m}$ \\
$b_{2} / D_{2}$ & 0.0216 \\
$Z$ & 13 \\
\hline
\end{tabular}

friction is the main loss source in the impeller as expected due to narrow flow path of low flow coefficient centrifugal compressor and increases gradually from surge side to choke side. Wake loss appears near surge point and presents the smallest loss coefficient. Minimum incidence loss occurs at design point. The distribution of incidence loss is pretty typical. Either increasing mass flow rate from design point to choke side or reducing it from design point to surge side will cause more incidence loss. Higher pressure ratio is always accompanied by accordingly higher blade loading loss, which can explain why blade loading loss distributes like the trend shown in Figure 6. An inducer diffusion loss appears only for applications of less than $63 \%$ mass flow rate, which is 


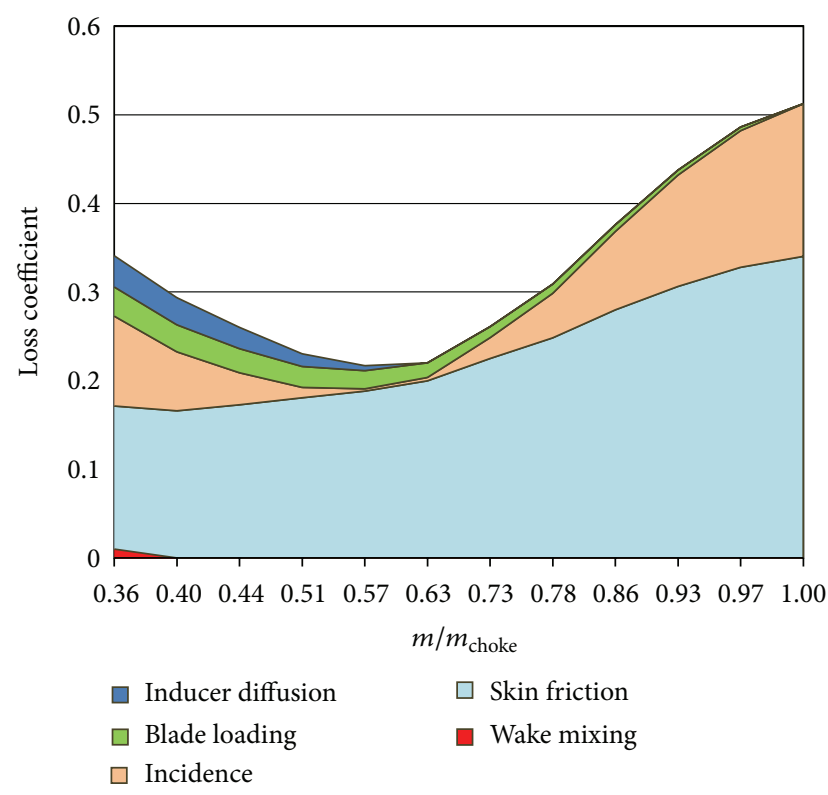

FIGURE 6: Loss coefficient distribution of impeller.

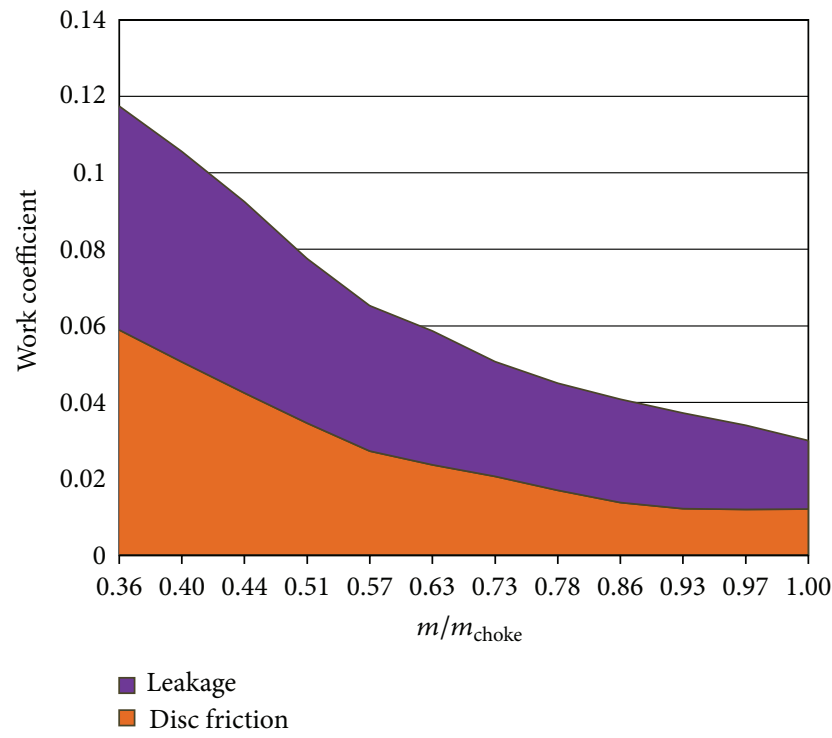

Figure 7: Distribution of work coefficient due to parasitic losses.

the design point. For parasitic losses or external losses, only disc friction loss and leakage loss are involved. They present similar distribution trend, seen in Figure 7. Overall, 1D code provides as much information as it can. More importantly, the 1D analysis results look reasonable and acceptable.

Note. Please refer to reference [2] to look up the equations used for calculating loss coefficient and work coefficient in Figures 6 and 7, which are based on the results that the analysis code provides.

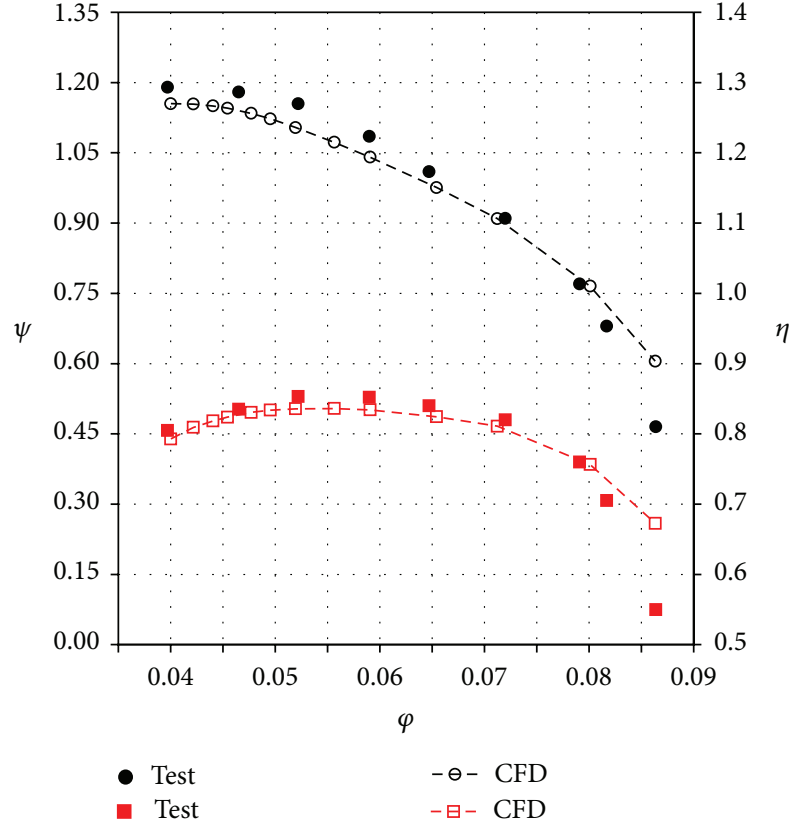

Figure 8: Performance comparison between test and CFD.

\section{3D CFD Validation}

Many impellers coming from either open literature or industry have been used to evaluate the accuracy of the CFD analysis before. It is confirmed that our CFD simulation is reasonable and reliable. An impeller similar to the case in this paper is chosen to present our CFD analysis accuracy compared to test data from a cooperative company. This impeller also applies two-dimensional blades and is used in the last stage centrifugal compressor of the multistage compressors. It can be observed in Figure 8 that CFD has a good agreement with test data.

Note. Vaneless diffuser and return channel are also involved in the test and CFD.

For the case in this paper, before running CFD, impeller modeling is built in the commercial software "BLADEGEN" according to the fixed geometry from $1 \mathrm{D}$ design code. Figure 9 shows the geometry and meridional view of the impeller. It can be observed that leading edge of impeller is in the radial direction and flow channel is so narrow, which are the typical characteristics of low flow coefficient centrifugal compressors. Inlet and outlet computational domains have to be added to avoid reserved flow and improve accuracy of computation in CFD. Extended outlet computational domain acts like practical vaneless diffuser and makes impeller run close to the real environment.

Three-dimensional, viscous RANS solver and SpalartAllamaras turbulent model are applied in the steady simulation with inlet boundary conditions of $P_{01}=13602 \mathrm{kPa}$, $T_{01}=424 \mathrm{~K}$, and axial flow. Static pressure is set on the outlet boundary condition and increased gradually. Near lower flow region, using mass flow rate condition captures stall point instead of static pressure condition. The working medium is 


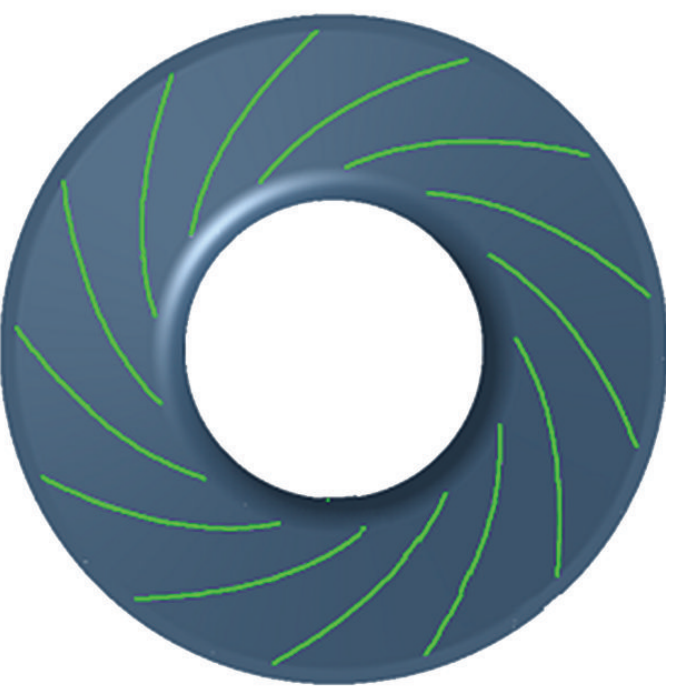

(a) Impeller geometry

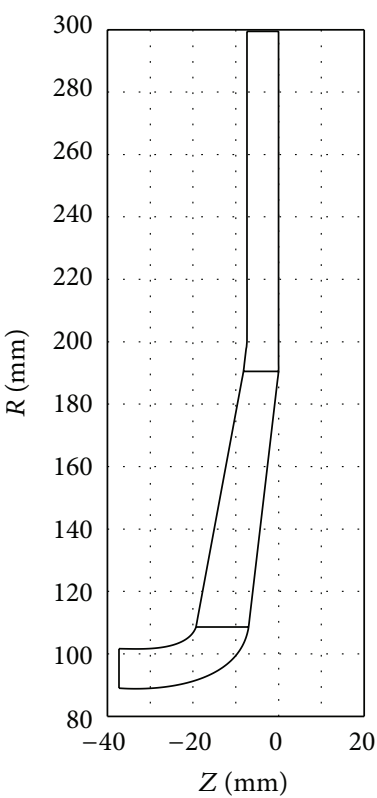

(b) Meridional view

FIGURE 9: Impeller design.

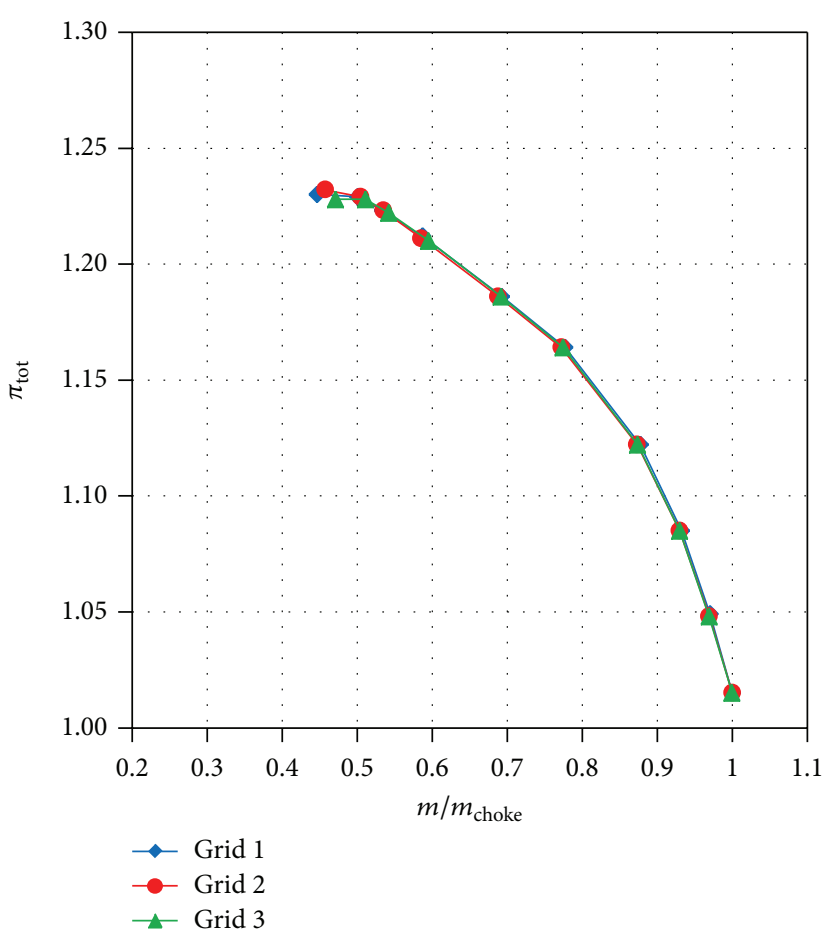

(a) Total pressure ratio

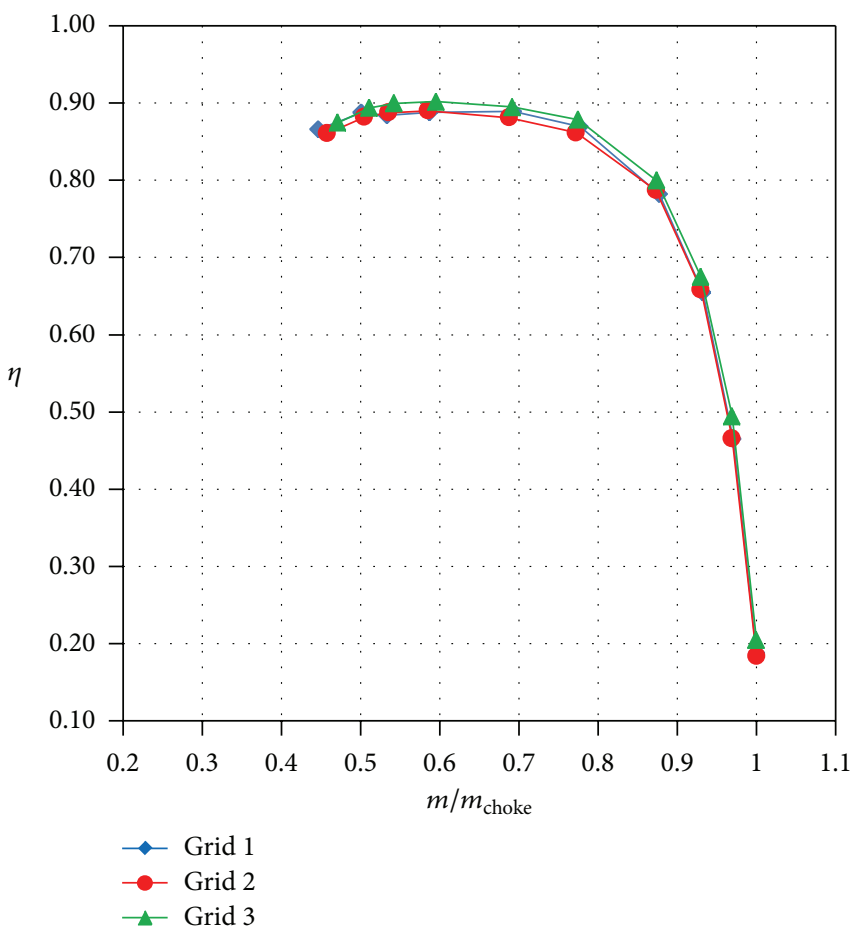

(b) Adiabatic efficiency

FIGURE 10: Simulation results with three grid plans.

defined as typical natural gas. All solid walls are assumed to be smooth with roughness of $10^{-6} \mathrm{~m}$. In order to reduce the effect of skin friction coefficient affected by surface roughness, same surface property has to be employed in 1D code when making a comparison between $1 \mathrm{D}$ prediction and CFD simulation.
In order to understand the analytical accuracy of the CFD on the impeller of this case, three grid plans shown in Table 2 were tried to check grid sensitivity. Figure 10(a) shows that total pressure ratio distribution curves from three grid plans match very well. Adiabatic efficiency curves seen in 
TABLE 2: Three grid plans.

\begin{tabular}{lcccc}
\hline & Circumferential & Streamwise & Spanwise & Grid number \\
\hline Grid 1 & 27 & 87 & 39 & 185367 \\
Grid 2 & 35 & 107 & 49 & 295421 \\
Grid 3 & 43 & 127 & 57 & 435309 \\
\hline
\end{tabular}

Figure 10(b) also present a good match. However, it seems that larger stall margin is obtained by applying less grid number. In consideration of running safety in the test, the grid plan 3 with smaller stall margin will be selected as a reference for design, because designers can not just pick the option with the best evaluation.

For adiabatic efficiency of impeller, 1D code can present the results with and without parasitic losses. However, CFD does not usually include parasitic losses unless the exact practical structure of centrifugal compressor is built. That is the reason why Figure 11(a) shows three distribution curves for efficiency. In addition to evaluate $1 \mathrm{D}$ code through comparing with CFD without parasitic losses, the efficiency including parasitic losses, close to real environment, is needed to be presented as well. 1D code shows wider operating range and further stall point, which means that, comparing with CFD, 1D code predicts that the centrifugal compressor can run at lower mass flow rate. It's shown that steady CFD simulation cannot get an accurate stall point. Transient simulation should be done after steady calculation, which is not completed in this paper. According to the comparison of efficiency, CFD has a little bit discrepancy in adiabatic efficiency on the right side of blue line. However, difference in efficiency becomes bigger and distribution trends show different as mass flow rate continues to be reduced.

In Figure 11(b), total pressure ratio from CFD is overpredicted but has same distribution trend with $1 \mathrm{D}$ prediction. Since empirical loss models are used in the code and CFD cannot show the exact results with real values, we think 1D code works well and has the function to finish the performance evaluation within acceptable discrepancy. Further validation with more impellers needs to be carried out in the future to see if a constant coefficient for total pressure ratio exists between 1D code and CFD. And if this is the case, the prediction accuracy of $1 \mathrm{D}$ code can be further improved.

Note. Equation (6) presents the efficiency without parasitic losses. However, parasitic losses are taken into account in (7). As mentioned before, these two equations are used to be compared with CFD and test data, respectively.

Relative Mach number distributions at 10\%, 50\%, and $90 \%$ spans are shown in Figure 12. It is very clear that a low velocity region exists near pressure surface and becomes smaller gradually as blade span increases. Because high static pressure near pressure surface accompanies low velocity, the low magnitude area can be expected near pressure surface. Moreover, narrow passage introduces large viscous effects and the typical velocity distribution of the bend comes up just before the leading edge of the impeller, which makes it obvious why Figure 12 presents relative Mach number like that. Fortunately, no flow separation is found in the flow field of the impeller.

Figure 13 shows $V_{m}$ distribution on the meridional view. No low flow region and separation bubble exist, which indicates that this design is rational. It is seen in Figure 13 that velocity is gradually increasing from hub to shroud in the extended inlet region, which is a typical flow distribution in the bend. High velocity means low static pressure, and vice versa. High pressure static pressure near hub region creates centripetal force to balance centrifugal force. In order to reduce the effect of this kind of flow distribution on the incidence angles along the span of impeller inlet, lower curvature of shroud in the extended inlet region, which can cause higher flow area and reduce hub-to-shroud velocity gradient, should be applied for performance optimization in the future. Figure 14 presents the idea that static pressure distribution is smooth through the impeller as expected.

Due to the even absolute flow angle distribution at impeller exit shown in Figure 15, vaneless or vaned diffuser has perfect inlet condition and can be easily designed if needed. Blade loading at $10 \%, 50 \%$, and $90 \%$ spans distributes reasonably, which can be checked out in detail in Figure 16. The blank area between pressure and suction surface static curves represents the load that blade withstands, which does not vary too much through the blade at different spans. That is what designers expect.

The main performance parameters comparison at design point is listed in Table 3. The power calculated by CFD is approximately in the middle of these two values computed by 1D code. Compared to CFD, the efficiency is overpredicted by $1.52 \%$ in the $1 \mathrm{D}$ code, which is really satisfying. The total pressure ratio in CFD is $3.05 \%$ higher than $1 \mathrm{D}$ code. In addition, parasitic losses drop efficiency a lot based on 1D prediction.

\section{Conclusions}

1D code is developed in this paper and divided into two parts, which are used to design and analyze. Based on the code, a low flow coefficient centrifugal compressor is designed and its performance is predicted. In comparison with $1 \mathrm{D}$ code, steady CFD simulation has been carried out and provides flow field details in the impeller.

Comparing to $1 \mathrm{D}$ code, $\mathrm{CFD}$ overpredicts total pressure ratio of impeller but shows the same distribution trend which is encouraging. Further validations through more impellers have to be done in the future to confirm if a constant coefficient for total pressure ratio exists between CFD and $1 \mathrm{D}$ code. For adiabatic efficiency, 1D code without including parasitic losses matches very well CFD in the operating range of near design point and choke point. However, 1D code is overpredicted between near design point and stall point. The difference of mass flow rate at choke point between CFD and $1 \mathrm{D}$ code is less than $2 \%$. Compared to steady CFD, $1 \mathrm{D}$ code presents stall point at lower mass flow rate. No flow separation is found in the flow field of impeller, and even the absolute flow angle distribution at impeller exit is shown. The 


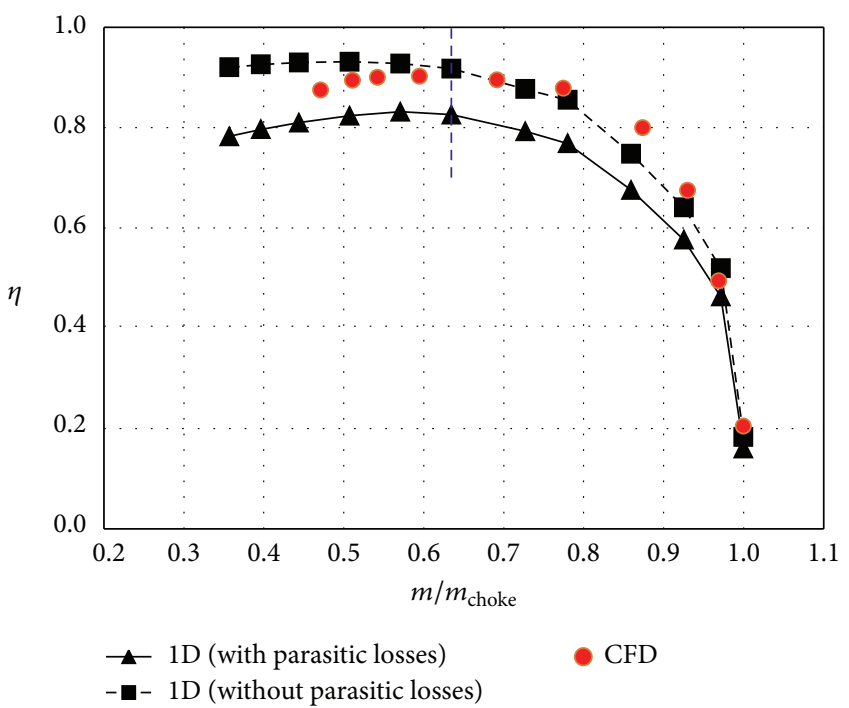

(a) Adiabatic efficiency

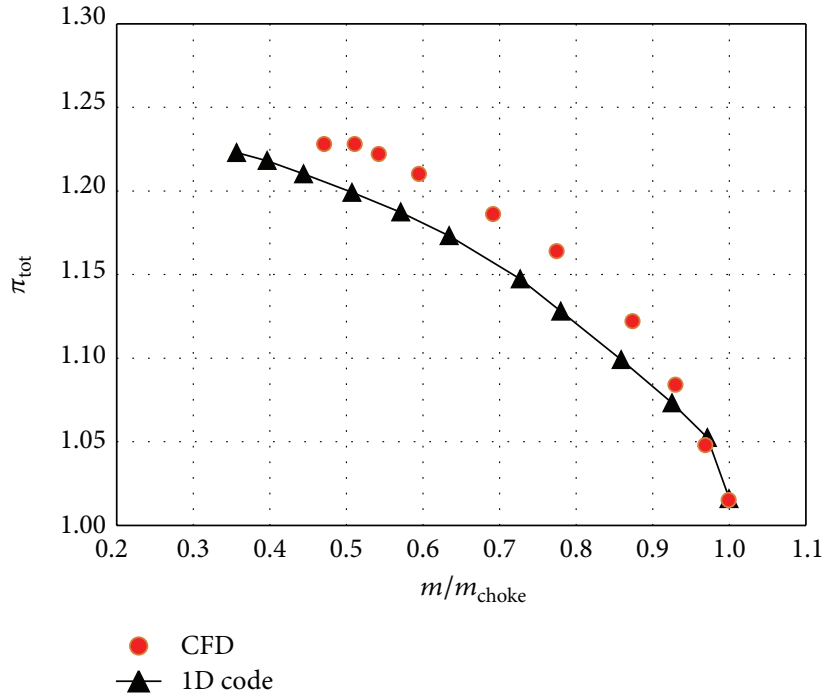

(b) Total pressure ratio

FIGURE 11: Impeller performance curves.
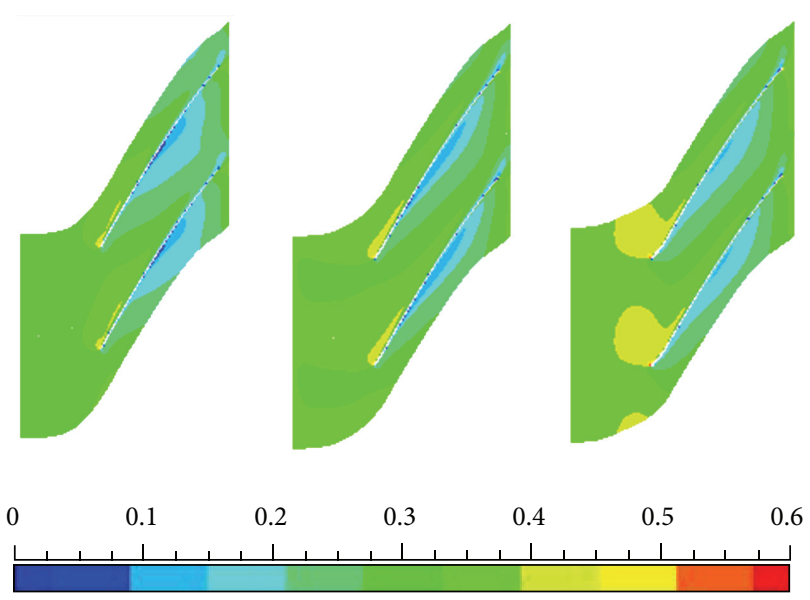

(a) $10 \%$ span

(c) $90 \%$ span

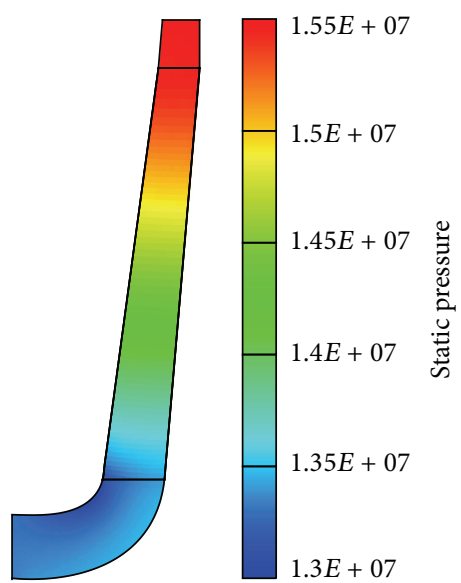

FIGURE 14: Static pressure distribution.

Figure 12: Relative Mach number map.

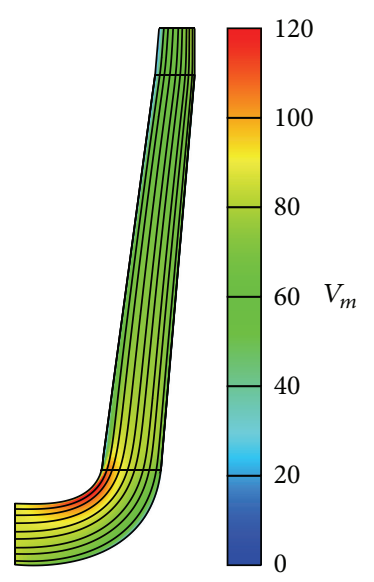

FIGURE 13: Meridional velocity and streamline distribution.

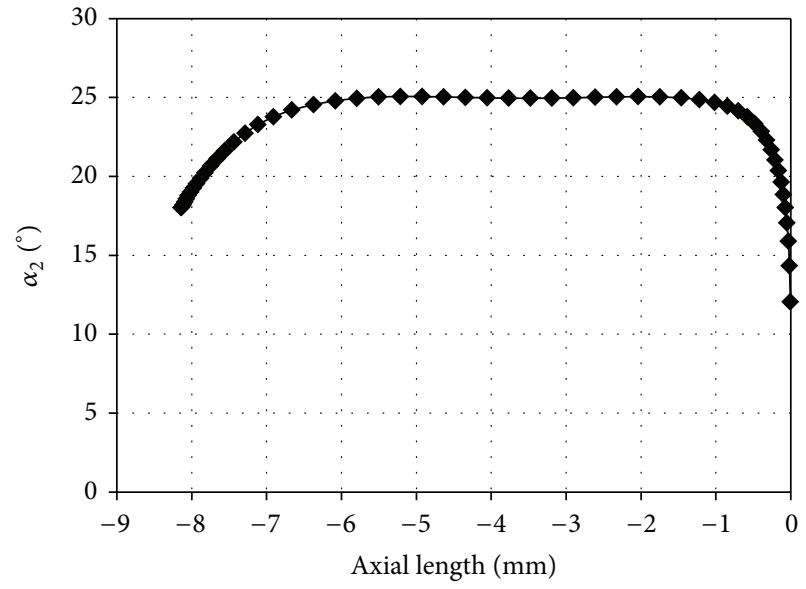

FIgURE 15: Absolute flow angle distribution at impeller exit. 


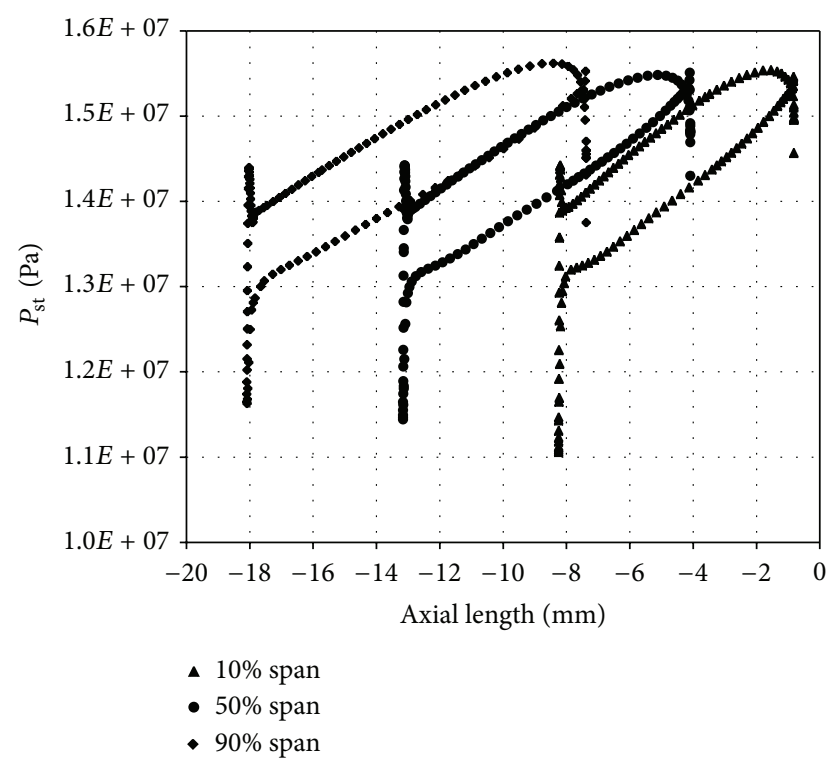

FIGURE 16: Blade loading distribution at different spans.

TABLE 3: Performance comparison between CFD and 1D code at design point.

\begin{tabular}{lccc}
\hline & CFD & 1D & 1D \\
& & (no parasitic losses) & (parasitic losses) \\
\hline Power & $1778400 \mathrm{~W}$ & $1656740 \mathrm{~W}$ & $1857339 \mathrm{~W}$ \\
$\pi_{\text {tot }}$ & 1.21 & 1.1731 & 1.1731 \\
$\eta$ & $90.2 \%$ & $91.72 \%$ & $82.57 \%$ \\
\hline
\end{tabular}

blade loading at three different spans distributes smoothly as expected.

Since the low flow coefficient centrifugal compressor designed in this paper is not the usual type and empirical equations used are based on medium flow coefficient compressors, further research on the improvement and validation of $1 \mathrm{D}$ code needs to be done by experiment and CFD to increase prediction accuracy.

\section{Nomenclature}

$$
\begin{array}{ll}
A: & \text { Area }\left(\mathrm{m}^{2}\right) \\
\text { AR: } & \text { Area ratio }\left(A_{2} \sin \left(\beta_{2 b}\right) / A_{1} \sin \left(\beta_{\mathrm{th}}\right)\right) \\
a: & \text { Sonic velocity }(\mathrm{m} / \mathrm{s}) \\
B: & \text { Fraction area blockage } \\
b: & \text { Blade height }(\mathrm{m}) \\
C_{p}: & \text { Specific heat at constant pressure } \\
& (\mathrm{J} / \mathrm{kg} \mathrm{K}) \\
e: & \text { Impeller mean line radius ratio } \\
D: & \text { Diameter }(\mathrm{m}) \\
D_{\text {eq }}: & \text { Equivalent diffusion factor } \\
k: & \text { Ratio of specific heats } \\
\Delta h: & \text { Enthalpy increase }(\mathrm{J} / \mathrm{kg}) \\
I_{B}: & \text { Blade work input coefficient, } \\
& \sigma\left(1-m \cot \left(\beta_{2 b}\right) /\left(\left(\rho_{2} A_{2} U_{2}\right)\left(1-B_{2}\right)\right)\right)- \\
& U_{1} C_{u 1} / U_{2}^{2}
\end{array}
$$

$L_{Z}:$ Impeller axial length $(\mathrm{m})$

$L_{B}$ : Length of blade mean camberline (m)

$M$ : Relative Mach number

$m$ : Mass flow rate $(\mathrm{kg} / \mathrm{s})$

$N$ : Rotation speed (rpm)

$N_{s}$ : Specific speed

$P: \quad$ Pressure (pa)

$R: \quad$ Gas constant $(\mathrm{J} /(\mathrm{kg} \cdot \mathrm{K}))$

$T: \quad$ Temperature $(\mathrm{K})$

$U: \quad$ Blade speed $(\mathrm{m} / \mathrm{s})$

$V: \quad$ Absolute velocity $(\mathrm{m} / \mathrm{s})$

$W:$ Relative velocity $(\mathrm{m} / \mathrm{s})$

$\Delta W$ : Average blade velocity difference $(\mathrm{m} / \mathrm{s})$

$Z$ : Number of the blades.

Greeks

$\alpha$ : Absolute flow angle from tangential $\left({ }^{\circ}\right)$

$\beta$ : $\quad$ Relative flow angle from tangential $\left({ }^{\circ}\right)$

$\eta$ : $\quad$ Adiabatic efficiency

$\lambda$ : Work/enthalpy coefficient, $\Delta h / U_{2}^{2}$

$\pi: \quad$ Pressure ratio

$\rho: \quad$ Gas density $\left(\mathrm{kg} / \mathrm{m}_{3}\right)$

$\sigma:$ Slip factor

$\varphi$ : Inlet flow coefficient, $m /\left(\rho_{1} U_{2} \pi D_{2}^{2} / 4\right)$

$\Psi$ : Inlet head coefficient,

$$
\left(854.4 / D_{2}\right)^{2} C_{p} T_{1}\left(\left(P_{2} / P_{1}\right)^{((k-1) / k)}-1\right)
$$

$\Delta \omega$ : Total pressure loss coefficient,

$$
\Delta p_{0} /\left(p_{0}-p\right) \text {. }
$$

\section{Subscripts}
0: Total condition
1: Impeller inlet
2: Impeller outlet
3: Diffuser inlet
4: Diffuser outlet

$\begin{array}{ll}b: & \text { Blade } \\ \text { bl: } & \text { Blade loading } \\ c: & \text { Criterion } \\ \text { choke: } & \text { Choke point } \\ \text { df: } & \text { Disc friction } \\ \text { dif: } & \text { Inducer diffusion } \\ h: & \text { Impeller inlet hub } \\ \text { hs: } & \text { Hub-to-shroud } \\ \text { inc: } & \text { Incidence } \\ \text { is: } & \text { Isentropic } \\ l: & \text { Leakage } \\ \text { lim: } & \text { Limit } \\ m: & \text { Meridional component } \\ \text { max: } & \text { Maximum } \\ \text { min: } & \text { Minimum } \\ \text { mix: } & \text { Wake mixing } \\ s: & \text { Shroud } \\ \text { st: } & \text { Static } \\ \text { th: } & \text { Impeller throat }\end{array}$




\author{
sf: Skin friction \\ tot: Total-to-total \\ $u$ : Tangential component \\ vld: Vaneless diffuser.
}

\section{Superscripts}

*: Correct value

I: New value

$\wedge$ : Value relative to rotating frame of reference.

\section{Conflict of Interests}

The authors declare that they have no financial and personal relationships with other people or organizations that can inappropriately influence their work; there is no professional or other personal interest of any nature or kind in any product, service, and/or company that could be construed as influencing the position presented in, or the review of, the paper.

\section{Acknowledgment}

This work is supported by the National Natural Science Foundation of China under Grant no. 51010007 and the China Scholarship Council (CSC). The authors would like to thank Dr. Marco Vagani and Christopher D. Bolin for their discussion and advice.

\section{References}

[1] T. Sato, J. M. Oh, and A. Engeda, "Experimental and numerical investigation of the flow in a vaneless diffuser of a centrifugal compressor stage. Part 1: experimental investigation," Proceedings of the Institution of Mechanical Engineers C, vol. 219, no. 10, pp. 1053-1059, 2005.

[2] R. H. Aungier, Centrifugal Compressor: A Strategy for Aerodynamic Design and Analysis, ASME Press, New York, NY, USA, 2000.

[3] V. Rusak, "Development and performance of the wedge-type low specific speed compressor wheel," Tech. Rep. 82-GT-214, ASME, 2009.

[4] M. V. Casey, P. Dalbert, and E. Schurter, "Radial compressor stages for low flow coefficients," in Proceedings of the IMechE International Conference on Machinery for the Oil and Gas Industries, 1990.

[5] T. Koizumi, "Experimental studies on performance of centrifugal compressors with very small flow coefficient," Mitsui Zosen Technical Review, vol. 117, pp. 28-39, 1983.

[6] J. Paroubek, J. Kyncl, and V. Cyrus, "Experimental investigation and performance analysis of six low flow coefficient centrifugal compressor stages," Transactions of the ASME: Journal of Turbomachinery, vol. 117, no. 4, pp. 585-592, 1995.

[7] J.-L. Di Liberti, Design and development of low-flow coefficient centrifugal compressors for industrial application [Ph.D. thesis], Michigan State University, 1998.
[8] Y. I. Biba, D. A. Nye, and L. I. U. Zheji, "Performance evaluation and fluid flow analysis in low flow stages of industrial centrifugal compressor," International Journal of Rotating Machinery, vol. 8, no. 5, pp. 309-317, 2002.

[9] M. R. Galvas, "Fortran program for predicting off-design performance of centrifugal com-pressors," Tech. Rep. TN D7487, NASA, 1973.

[10] K. H. Lüdtke, Process Centrifugal Compressors: Basic, Function, Operation, Design, Application, Springer, Berlin, Germany, 2010.

[11] F. J. Wiesner, "A review of slip factors for centrifugal compressors," Journal of Engineering for Power Transactions of the ASME, vol. 89, pp. 558-572, 1967.

[12] R. H. Aungier, "Mean streamline aerodynamic performance analysis of centrifugal compressors," Transactions of the ASME: Journal of Turbomachinery, vol. 117, no. 3, pp. 360-366, 1995.

[13] S. L. Dixon, Fluid Mechanics and Thermodnamics of Turbomachinery, Butterworth-Heinemann, 4th edition, 1998.

[14] Y. Senoo and Y. Kinoshita, "Limits of rotating stall and stall in vaneless diffusers of centrifugal compressors," Tech. Rep. 78GT-19, ASME, 1978.

[15] S. Lieblein, "Loss and stall analysis of compressor cascades," ASME Transactions, Journal of Basic Engineering, vol. 81, pp. 387-400, 1959.

[16] H. Krain and B. Hoffmann, "Flow physics in high pressure ratio centrifugal compressors," in Proceedings of the ASME Fluids Engineering Division Summer Meeting, June 1998.

[17] G. Eisenlohr and H. Krain, "Investigation of the flow through a high pressure ratio centrifugal impeller," in Proceedings of the ASME Conference Proceedings, 2003. 

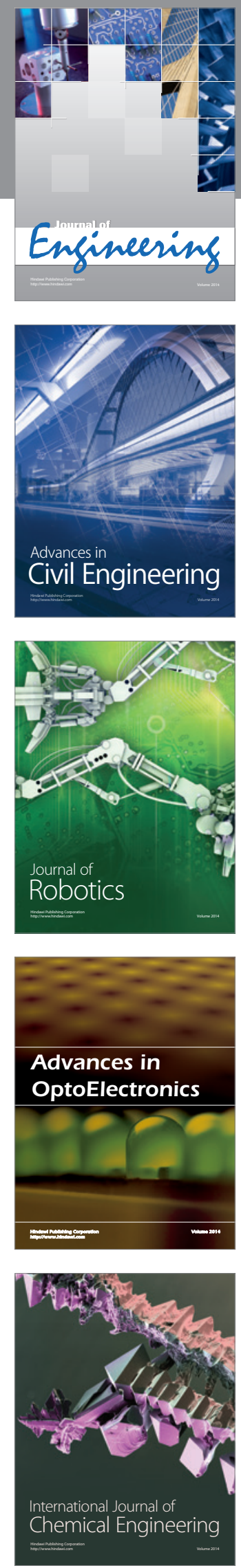

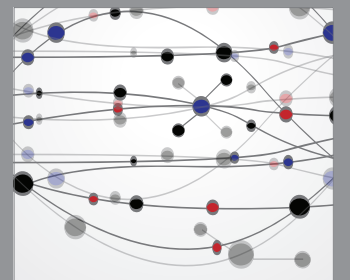

The Scientific World Journal
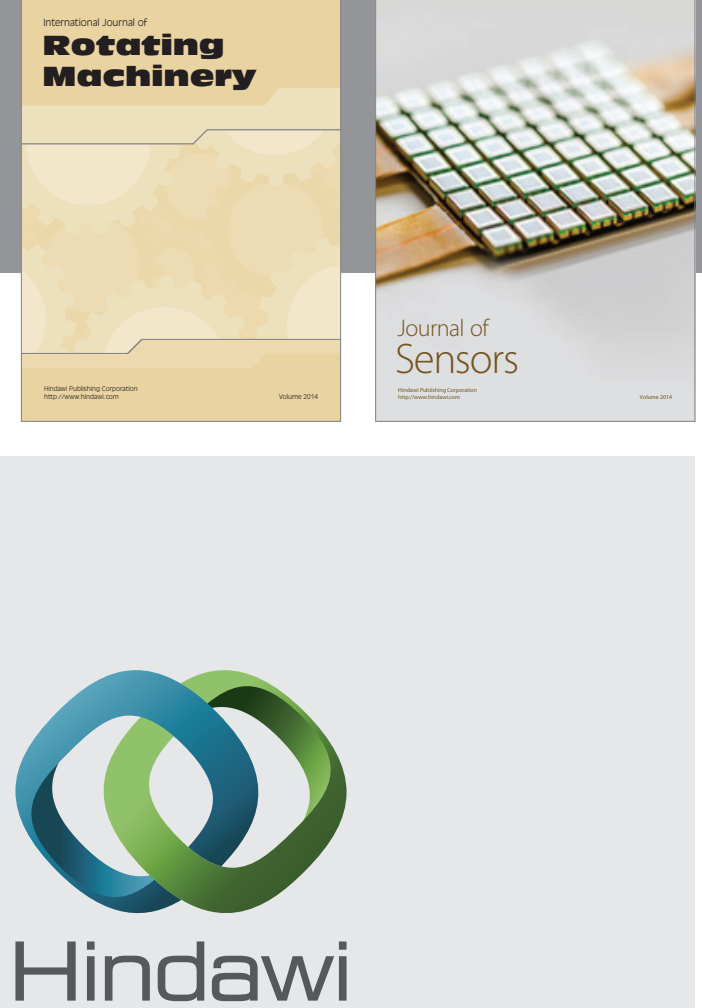

Submit your manuscripts at http://www.hindawi.com
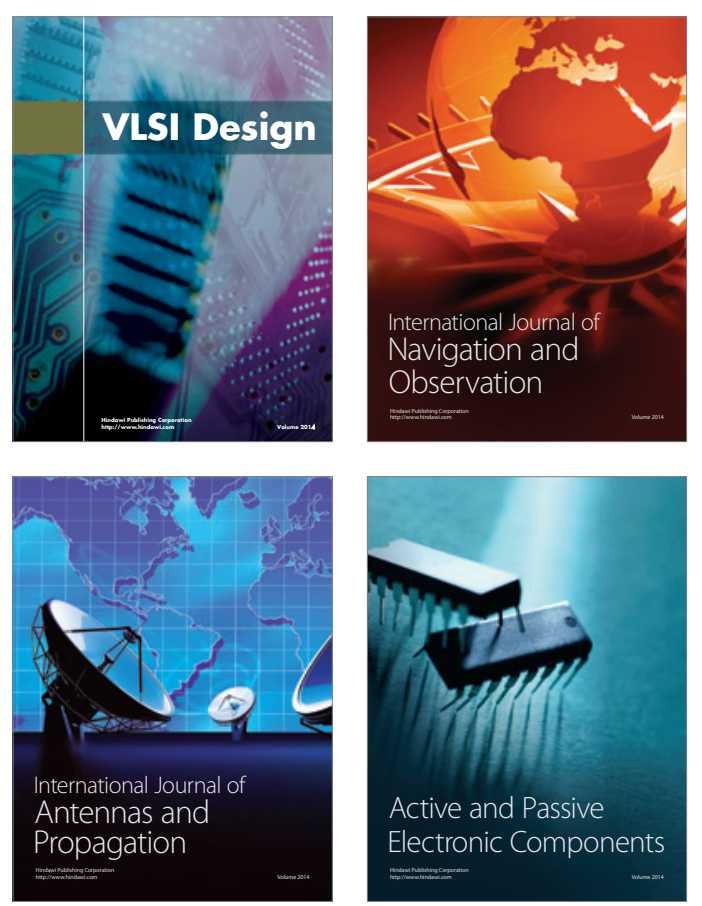
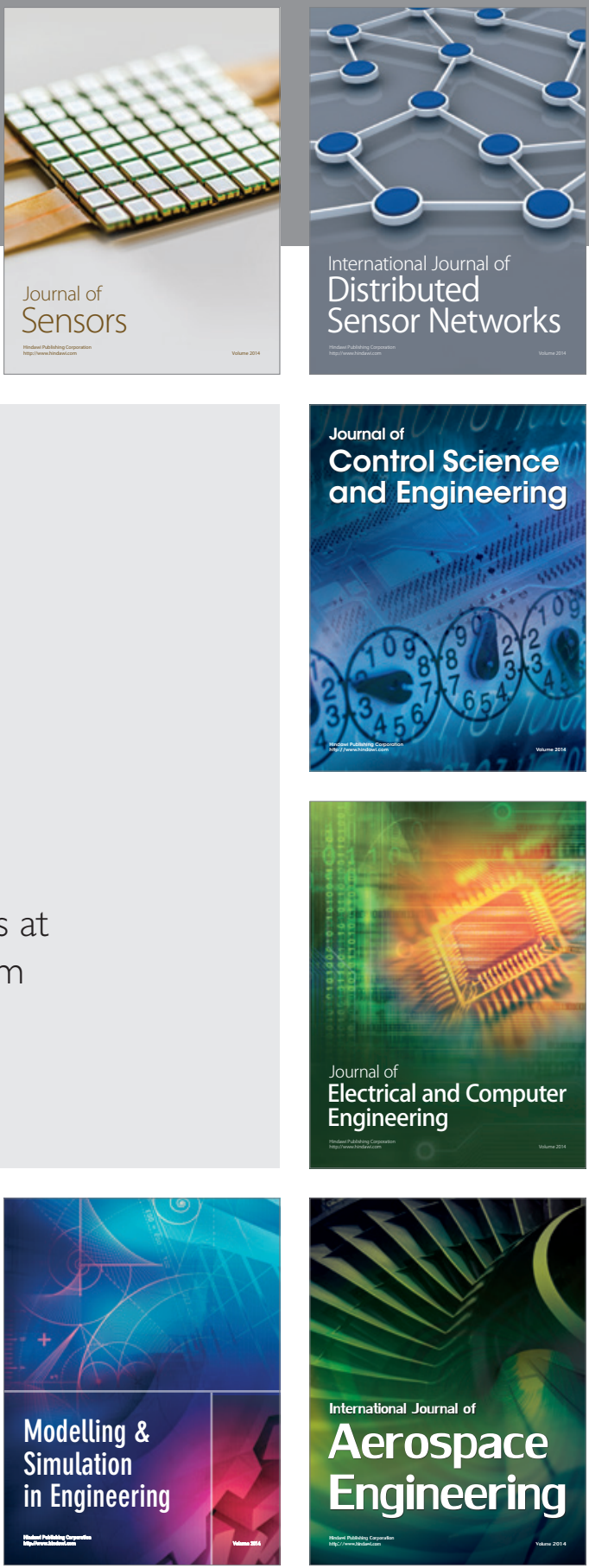

Journal of

Control Science

and Engineering
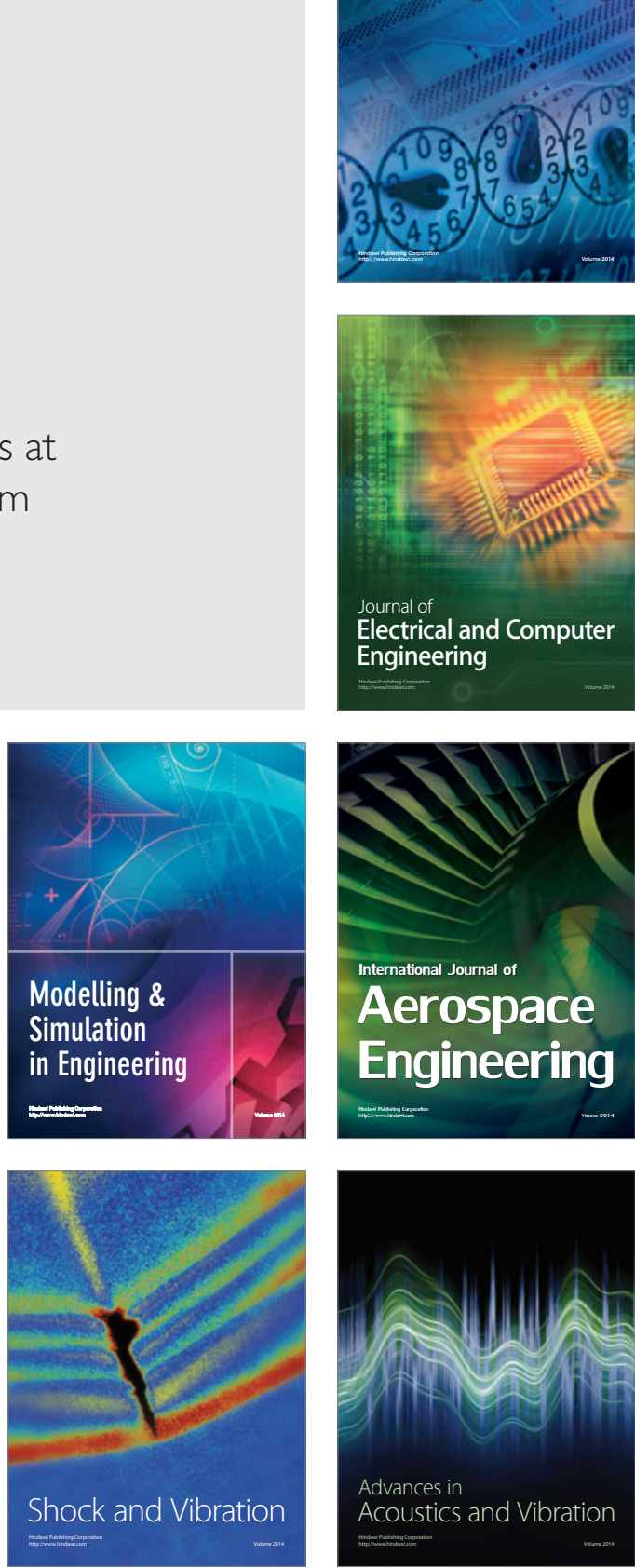